American Journal of Environmental Sciences 6 (3): 268-274, 2010

ISSN 1553-345X

(C) 2010 Science Publications

\title{
The Effect of High Altitude on Blood Hormones in Male Westar Rats in South Western Saudi Arabia
}

\author{
Fahaid H. Al-Hashem \\ Department of Physiology, College of Medicine, \\ King Khalid University, Abha 641, P.O. Box 641, Saudi Arabia
}

\begin{abstract}
Problem statement: Living in high altitude areas results in chronic hypoxia, which induces complex metabolic and endocrine adaptations. The current study investigated the endocrine responses of male Westar rats chronically exposed to high altitude-induced hypoxia in Abha City, in Southwestern Saudi Arabia. Approach: The rats were separated in to 2 groups of 10 rats. The first group was kept at an altitude of $600 \mathrm{~m}$ above sea level in the King Saud University animal house in Riyadh City and designated the low altitude group; the second group of rats was transferred to the King Khalid University animal house in Abha City, which is $2800 \mathrm{~m}$ height above sea level and was designated the high altitude group. All rats were housed under the same laboratory conditions and fed the same diet. Blood samples were collected from both groups of animals 45 days after transferring the high altitude group to Abha City. Results: The data revealed that the rats transferred to the high altitude area had significant decreases in serum Thyroid Stimulating Hormone (TSH) and testosterone levels and significant increases in the levels of serum cortisol, free Triiodothyronine (T3) and free Thyroxin (T4) compared to rats kept at low altitude. Conclusion: The current study demonstrates that rats chronically exposed to high altitude hypoxia experienced alternations in various hormones. These findings will contribute to a better understanding of human endocrine and metabolic physiology in hypoxic conditions.
\end{abstract}

Key word: High altitude, hormones, TSH, testosterone, Saudi Arabia

\section{INTRODUCTION}

The health effects of high altitude-induced hypoxia has long been considered important because a large number of people live at high altitudes and many others like to visit such areas for trekking, climbing or athletic training. The composition of the air stays the same but the total barometric pressure falls as altitude increases. As a result, the partial pressure of oxygen decreases and a state of hypoxia occurs (Michiels, 2004). Certain biochemical, physiological and microanatomical responses occur during acclimatization and adaptation to chronic hypoxia of high altitude (Ward et al., 1989). Therefore, the adaptive processes that occur in response to hypoxia indicate complex modifications in the homeostatic steady state of endocrine and metabolic functions (Michiels, 2004).

Altitude exposure is known to stimulate the neuroendocrine systems as part of the acute hypoxic and chronic adaptive acclimatization process (Asano et al., 1997). Indeed, the response to high altitude has been intensely investigated in terms of energy utilization (Westerterp and Kayser, 2006; Hamad and Travis, 2006) but data regarding endocrine adaptations are limited and conflicting (Krishnamachary et al., 2003). Additionally, though exposure to high altitude adversely affects male reproduction in both humans and animals (Monge, 1943; Abelson, 1976), the mechanisms responsible for these affects are not well understood and relatively few studies have examined how high altitude impacts the concentration of reproductive hormones. Abha City, located in Southwestern Saudi Arabia, is at an altitude of $2800 \mathrm{~m}$ above sea level (Climate Atlas of Saudi Arabia, 1988) and, to the best of our knowledge, no study has been conducted to investigate the effect of Abha's altitude on hormone levels. Therefore, the aim of the present study is to investigate the effects of the altitude of Abha city on the serum concentration of thyroid hormones, cortisol and testosterone in male rats.

\section{MATERIALS AND METHODS}

Areas of the study (Fig. 1): The study was carried out at areas of high and low altitude in different regions in the Kingdom of Saudi Arabia between January and February 2010. The high altitude area was in the Abha region, specifically, Abha city, the capital city of Aseer 
province $($ population $=352,303)($ Central Department of Statistic and Information, 2004) which is located in the Aseer mountains and has an altitude of 2800$3150 \mathrm{~m}$ above sea level. It has the lowest mean annual temperature of any of the Southern urban areas, a low atmospheric oxygen pressure and a high annual rainfall, with rain falling mainly in winter and spring (Climate Atlas of Saudi Arabia, 1988). The low altitude area selected was Riyadh, the capital of Saudi Arabia, which is located in the center of Saudi Arabia at latitude $38.24^{\circ}$ North and longitude $43.46^{\circ}$ East and rises about $600 \mathrm{~m}$ above sea level. Essential geographical information for each city, such as temperature, humidity and altitude, were collected from the related meteorological organizations. Environmental data on these areas are shown in Table 1.

Rats and experimental design: (Fig. 2): Twenty adult male Wistar rats (200-250 g) were used for the experiments with the approval of the Ethical Committee in the Department of Physiology at the King Khalid University Medical School (Abha, Saudi Arabia). All animals were bred and maintained in the animal house at King Saud University in Riyadh, College of Pharmacy.

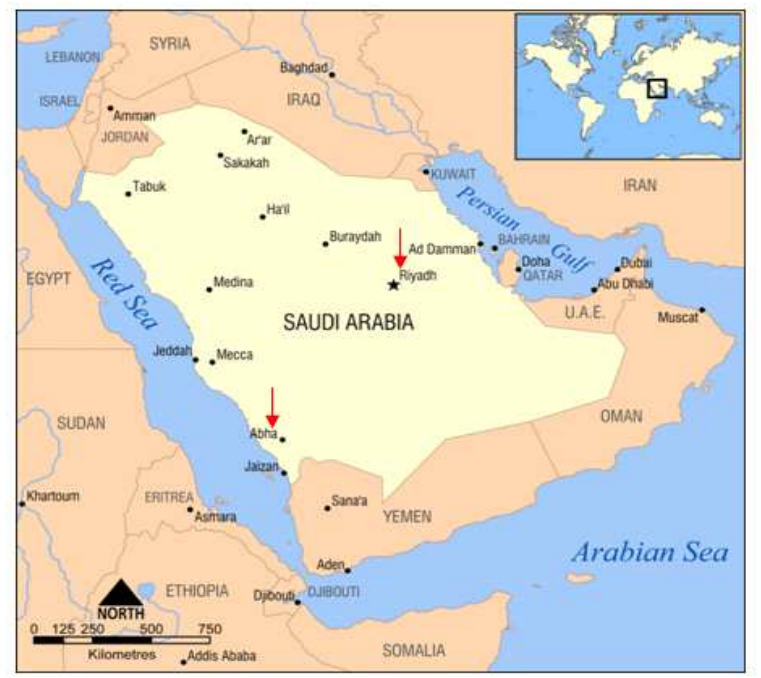

Fig. 1: Map of Saudi Arabia showing the location of the cities used in the current study (red arrows)

Table 1: Environmental data on the high and lowlands of the study

\begin{tabular}{lll}
\hline Data & $\begin{array}{l}\text { Highland } \\
(\text { Abha })\end{array}$ & $\begin{array}{l}\text { Lowland } \\
\text { (Riyadh) }\end{array}$ \\
\hline Altitude (meters) & $2800-3150$ & 600 \\
Barometric pressure $(\mathrm{mm} \mathrm{Hg})$ & $550-590$ & 711 \\
Atmospheric $\mathrm{O}_{2}$ tension $(\mathrm{mm} \mathrm{Hg})$ & $110-120$ & 145 \\
Relative humidity $(\%)$ & $20-30$ & $15-50$ \\
Summer temperature (shade) $\left({ }^{\circ} \mathrm{C}\right)$ & $16-28$ & $25-45$ \\
Winter temperature $\left(\right.$ shade) $\left({ }^{\circ} \mathrm{C}\right)$ & $5-15$ & $10-25$ \\
\hline
\end{tabular}

The rats were separated into 2 groups of 10 rats, the low altitude group and the high altitude group. The low altitude group was kept at King Saud University animal house in Riyadh City and the high altitude group was transferred to the animal house at the Medical School at King Khalid University in Abha City. Both groups were maintained in polypropylene cages of standard dimensions at a temperature of $25 \pm 1^{\circ} \mathrm{C}$, had a standard $12 \mathrm{~h}$ day/night cycle and were housed in groups of 5 rats per cage $(50 \times 26 \times 16 \mathrm{~cm})$. All procedures were performed in agreement with the Principles of Laboratory Animal Care, advocated by the National Society of Medical Research and the Guide for the Care and Use of Laboratory Animals, published by the National Institutes of Health.

Forty-five days after the high altitude group arrived at Abha City, both groups of rats were anaesthetized using ether. A blood sample was taken directly from the heart and placed in plain tubes where they were allowed to clot at room temperature. Samples were centrifuged at $4000 \mathrm{rpm}$ for $10 \mathrm{~min}$ to obtain serum for determining Thyroid Stimulating Hormone (TSH), free Triiodothyronine (T3), free Thyroxin (T4), cortisol and testosterone levels using specific, commercially available ELISA kits according to the manufacture's instructions.

Statistical analysis: Data analysis. Results were expressed as the mean value \pm SD. Statistical differences between groups were assessed using the SPSS software, version 16 and a Student's t-test. Values of $\mathrm{p}<0.05$ were considered significantly different (95\% Confidence interval).

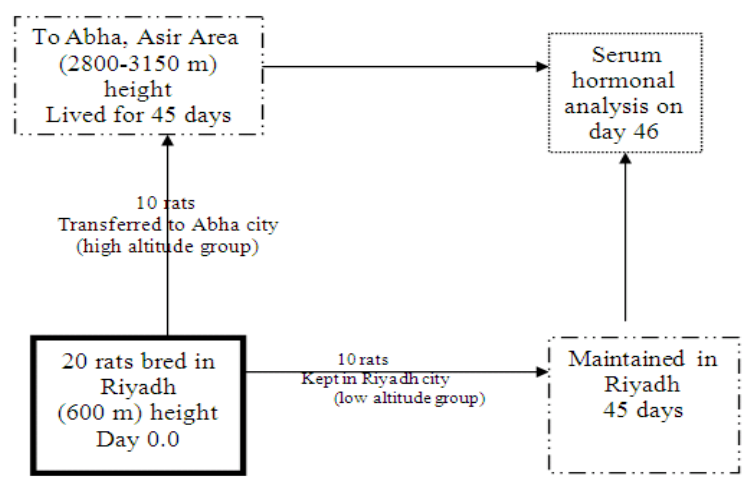

Fig. 2: Schematic of the experimental procedure

Table 2: The levels of Free T3 (FT3), Free T4 (FT4) and ThyroidStimulating Hormone (TSH) in the Low Altitude (LA) and High Altitude (HA) groups of rats

\begin{tabular}{llll}
\hline Group & FT3 $\left(\mathrm{pmol} \mathrm{L}^{-1}\right)$ & FT4 $\left(\mathrm{pmol} \mathrm{L}^{-1}\right)$ & TSH $\left(\mathrm{uIUmL}^{-1}\right)$ \\
\hline LA & $2.33 \pm 0.090$ & $8.69 \pm 1.33$ & $0.281 \pm 0.037$ \\
HA & $3.42 \pm 0.691^{*}$ & $26.98 \pm 1.23^{*}$ & $0.027 \pm 0.048^{*}$ \\
\hline
\end{tabular}

Values are given as mean \pm SD for each group. *: Values are statistically significant, $\mathrm{p}<0.05 \mathrm{HA}$ rats were compared with LA rats 
Am. J. Environ. Sci., 6 (3): 268-274, 2010

Table 3: Blood levels of testosterone and cortisol in the Low Altitude (LA) and High Altitude (HA) groups of rats

\begin{tabular}{lll}
\hline Group & Testosterone $\left(\mathrm{ng} \mathrm{mL}^{-1}\right)$ & Cortisol $\left(\mathrm{nmol} \mathrm{L}^{-1}\right)$ \\
\hline LA & $3.09 \pm 0.356$ & $8.136 \pm 2.98$ \\
HA & $1.20 \pm 0.489^{*}$ & $33.36 \pm 3.98^{*}$ \\
\hline
\end{tabular}

Values are given as mean \pm SD. *: Values are statistically significant, $\mathrm{p}<0.05$. LA rats were compared with HA rats

\section{RESULTS}

Hormone levels in the high and low altitude rat groups are shown in Table 2 and 3.

Chronic exposure to high altitude lead to a significant decrease in TSH and a significant increase in the levels of free $\mathrm{T} 3$ and free $\mathrm{T} 4$ in the serum compared to animals maintained at low altitude (Table 2). Additionally, there was also a significant increase in serum cortisol and a significant decrease in testosterone levels in rats kept at high altitude compared to animals housed at the lower altitude (Table 3).

\section{DISCUSSION}

The results presented in this study demonstrate that rats transferred and maintained in a facility at a high altitude develop significant hormonal changes compared to animals kept at a low altitude. These changes included a significant decrease in TSH and testosterone levels and a significant increase in the levels of serum cortisol, free T3 and free T4 compared to rats maintained at low altitude. All rats were housed under the same laboratory conditions and were fed the same diet; thus, the observed hormonal changes were not due to dietary factors or to adaptive evolutionary changes (Golstein-Golaire et al., 1970). Furthermore, racial factors were eliminated as this study was done in rats rather than humans and all animals were born and bred in the same facility. Thus, the factor that appears to be at study in this situation is environmentally derived. There are distinct differences between male and female rats with regard to TSH, T3 and T4 levels and, of course, testosterone. TSH and T3 are present at higher concentrations in female rats than in male rats, $\mathrm{T} 4$ occurs in a higher concentration in male rats than in female rats and cycling female rats have a cycleassociated biorhythm for TSH (Campbell et al., 1977). Therefore, to eliminate any sex-related differences, we only used male rats. To minimize the diurnal variation of hormone levels, all of the samples were collected in the morning around 10:00 am.

Thyroid hormone mediates the release thyroxine to the peripheral tissues in response to perturbations induced by the external environment, chemicals and drugs and a variety of disease processes. The thyroid gland secretes two separate amino acid iodine-bound thyroid hormones known as T3 and T4 (thyroxine), both of which are also found in a free form and are important in the regulation of general metabolism, growth and tissue differentiation, as well as gene expression (Braverman and Utiger, 2000). ThyrotropinReleasing Hormone (TRH), secreted from the hypothalamus, stimulates the anterior pituitary to release thyrotropin, which is also known as TSH (Braverman and Utiger, 2000).

The influence of hypoxia on thyroid activity in humans and animals has been studied by several investigators (Mordes et al., 1983; Hornbein, 1962; Moncloa et al., 1965) and most have reported a reduction in thyroid activity. Surks (1966) reported an increase in the concentration of free thyroxine in humans due to altitude exposure; this was reflected in the elevation of basal oxygen consumption. Several investigators (Mordes et al., 1983; Hornbein, 1962; Moncloa et al., 1965) have also claimed that hypoxia influences the metabolism of iodine in the thyroid at various stages. A low TSH level in the blood of rats exposed to $250-280 \mathrm{~mm} \mathrm{Hg}$ pressure for 2-3 weeks was reported by Gordon et al. (1943).

Furthermore, a previous study in subjects who had a short-term stay at extremely high altitude while climbing mountain Everest reported an increase in total $\mathrm{T} 4$ and $\mathrm{T} 3$ concentrations associated with an increase in TSH levels (Mordes et al., 1983). However, it has been reported that significant elevations in free T4 levels can occur after 3 weeks at $4300 \mathrm{~m}$ without any change in TSH levels (Barnholt et al., 2006). Our present findings, recorded after 45 days at a high altitude, $2800 \mathrm{~m}$, demonstrated that TSH significantly decreased while free T4 and free T3 levels increased. An increase in thyroid hormones has been explained as a response to hypoxic stress (Sawhney and Malhotra, 1991; Basu et al., 1995) or, alternatively, as a function of alterations in the regulation of thyrotrophin via decreased TSH secretion (Mordes et al., 1983). The Hypothalamic-PituitaryThyroid (HPT) axis is physiologically important for regulating body growth and development, in particular development of the brain and energy-metabolismbalance and expenditure (Tamasy et al., 1986). TSH and the thyroid hormone axis are influenced by several factors; they are controlled by the hypothalamic Thyrotropin Releasing Hormone (TRH), a crucial regulator of the HPT axis. Hypoxia, as an non-stress factor, altered HPT function (Tamasy et al., 1986). Following exposure to high altitude, decreased thyroid function has been observed in animals (Heath and Williams, 1977). Hypoxia $\left(10 \% \mathrm{O}_{2}\right)$ suppresses TRH mRNA expression in the paraventricular nucleus of the 
rat hypothalamus both sub-acutely and chronically (Hirooka et al., 1978) and this may explain the decrease in TSH seen in our study. Additionally, somatostatin suppresses TRH release (Du, 1998; Hirooka et al., 1978; Tapia-Arancibia et al., 1984) and it may play an important role in inhibiting TRH, thereby decreasing TSH levels (Hirooka et al., 1978; Tapia-Arancibia et al., 1984).

Furthermore, large individual variability has been observed in the changes in cortisol and testosterone that occur under conditions of physical exertion (Sutton et al., 1973; Fry et al., 1991). Testosterone is a steroid hormone produced and secreted by the Leydig cells in the testes and has both anabolic and anti-catabolic effects on muscle tissues (Sutton et al., 1973; Volek et al., 1997). Cortisol is a steroid hormone released by the adrenal cortex that has catabolic effects on muscle tissues (Adlercreutz et al., 1986). During conditions of stress, such as intense training, cortisol and testosterone have been reported to change significantly (Volek et al., 1997; Adlercreutz et al., 1986). Hypoxia is known to modify cortisol release, although its effects depend on the experimental conditions. However, resting plasma cortisol concentrations have been reported to increase (Moncloa et al., 1968; Humpeler et al., 1980) or remain unchanged (Sutton, 1977), in humans exposed to acute hypoxia. During physical exercise at altitude, or under simulated hypoxia, the plasma cortisol response was greater than at sea level (Richalet et al., 1989). Moreover, it has been recorded that Adrenocorticotropin (ACTH) increases in high altitude in people at rest and during exercise (Richalet et al., 1989). This result may reflect a reduction in adrenal sensitivity to ACTH in people exposed to hypoxia. Our results show that hypoxia has stimulatory actions on cortisol secretion. Hypoxia acts as an external stressor and increases sympathetic tone, suggesting that hypoxia causes a shift in the sympatho-vagal nerve interaction at rest toward sympathetic dominance. This sympathetic activation may results in an increase in ACTH, which stimulates the secretion of cortisol by the adrenal gland (Richalet et al., 1989).

Given that a decrease in gonadal hormones has often been reported during exposure to high altitude (Vaernes et al., 1984; Basu et al., 1997) and plasma testosterone has been implicated as a hormonal marker of fatigue (Hackney et al., 1988), we set out to study the effects of prolonged hypoxia exposure on serum testosterone levels in rats. Moreover, a decrease in fertility among people exposed to altitude, particularly for newcomers, has been described (Eckes, 1976). Among the many factors, hypoxia may play a role in this impairment of fertility, but this is controversial
(Bangham and Sacherer, 1980; Godoy, 1984; Wiley, 1998). Data in the literature are mainly concerned with only female fertility and there is less information regarding male fertility. A decrease in salivary testosterone was found in men native to areas at an altitude of $3600 \mathrm{~m}$, i.e., 12,000 ft., compared with lowlanders (Beall et al., 1992). In pathology cases, high plasma concentrations of Luteinizing Hormone ( $\mathrm{LH})$, in association with low testosterone, were found in patients with chronic obstructive lung disease (Gow et al., 1987). Moreover, the decrease in testosterone and its precursors in the spermatic vein and in the testicular tissue of elderly men may be the result of an impaired oxygen supply (Pirke et al., 1980). In male animals, prolonged hypoxic exposure may lead to a degeneration of the testes and azoospermia (Eckes, 1976). It has been previously demonstrated that male rates respond to hypobaric hypoxia with cardiovascular changes similar to those exhibited in humans in highaltitude conditions, validating the use of an animal model to study the physiological adaptations to hypobaric hypoxia (Richalet et al., 1992; Germack et al., 2002; Farias et al., 2005). Also, exposure of male rats to hypobaric hypoxia has been shown to promote a reduction in testicular mass, deterioration of interstitial cells, increase in the interstitial space, damage to the germinal epithelium and an increase in the seminiferous tubule lumen. Furthermore, loss of spermatogenic cells and a strong metabolic stress response in these cells were observed (Gosney, 1984; Richalet et al., 1992)

In our current study, we found a significant decrease in serum testosterone levels in rats exposed to hypobaric hypoxia for a period of 45 days compared to animals kept at a lower altitude. Mayfield (1980) explained that the neuroendocrine effects of stress are mediated by the hypothalamus. CorticotrophinReleasing Hormone (CRH) neurons, present in hypothalamus, summate a large variety of neuronal and hormonal signals that arise in various regions of the nervous system. This specific hypothalamic neurohormone eventually either stimulates or inhibits hypophyseal activity in response to stress. Knol (1991) proposed that stressors generally induce depression of the hypothalamic-pituitary-testis system, which is mediated by the activation of the hypothalamicpituitary-adrenocortical system, resulting in a decrease in plasma $\mathrm{LH}$ and testosterone levels. CRH induces the release of endogenous opioids from the hypothalamus, which, along with corticosteroids, suppresses the secretion of hypothalamic Gonadotrophin-Releasing Hormone (GNRH). Suppression of the secretion of GNRH leads to reduced secretion of $\mathrm{LH}$ and FSH from the pituitary, which in turn causes a decrease in the testosterone level and in spermatogenesis. 
In response to hypoxic stress, Orr and Mann (1992) found that restraint stress caused increases in the plasma level of glucocorticoids and decreases in the testosterone level without any effect on the LH level. He suggested that the increase in the plasma level of glucocorticoids act, via glucocorticoid receptors on testicular interstitial cells, to suppress the testicular response to gonadotropins. Findings reported by Givern and Redei (1994) supported the primary role of glucocorticoids in stress-induced inhibition of the reproductive function in rats. Moreover, there is now ample evidence demonstrating that Nitric Oxide (NO) impairs steroid hormone synthesis in nearly all steroidogenic tissues, most probably by binding the heme in the cytochrome P450 enzymes or by forming nitrosothiol on cysteine residues adjacent to the heme (Panesar, 2000). It has been shown that treatment of rats with a precursor of NO (nitrite) in their drinking water for 4 weeks lowered the circulating levels of corticosterone and testosterone (Panesar and Chan, 2000). The activity of the hepatic cytochrome P450 enzymes, which metabolizes compounds including steroids, was impaired at high altitude, again perhaps due to NO (Jurgens et al., 2002). Although, currently, there are no reported human studies implicating nitrates and nitrite ions in lowering steroid hormones, there is certainly much discussion regarding environmental nitrates (and nitrites) and their role as endocrine disrupters (Pelley, 2003).

\section{CONCLUSION}

The current study demonstrated that rats exposed to chronic hypobaric hypoxia at an altitude of $2800 \mathrm{~m}$ displayed a significant decrease in TSH and testosterone levels accompanied by a significant increase in cortisol, FT3 and FT4 serum levels. These findings contribute to a better understanding of endocrine and metabolic physiology in hypoxic conditions.

\section{ACKNOWLEDGMENT}

The researchers thanks Mr. Mahmoud AL-Khateeb from the Department of Physiology at College of Medicine of King Khalid University for his contribution to the current study by helping in experimental designing and performing the biochemical measurements. Also thanks to the staff of Animal House of College of Pharmacy at King Saud University, Riyadh.

\section{REFERENCES}

Abelson, A.E., 1976 Altitude and fertility. Hum. Biol., 48: 83-92. http://www.jstor.org/pss/678983

Adlercreutz, H., M. Harkonen, K. Kuoppasalmi, H. Nveri and I. Huhtaniemi et al., 1986. Effect of training on plasma anabolic and catabolic steroid hormones and their response during physical exercise. Int. J. Sports Med., 7: 27-28. PMID: 3744643

Asano, K., R.S. Mazzeo, R.E. McCullough, E.E. Wolfel and J.T. Reeves, 1997. Relation of sympathetic activation to ventilation in man at $4300 \mathrm{~m}$ altitude. Aviat Space. Environ. Med., 68: 104-110. PMID: 9125085

Bangham, C.R. and J.M. Sacherer, 1980. Fertility of Nepalese Sherpas at moderate altitudes: Comparison with high-altitude data. Ann. Hum. Biol., 7 : 323-330. 10.1080/03014468000004391

Barnholt, K.E., A.R. Hoffman, P.B. Rock, S.R. Muza and F.C.S. Braun et al., 2006. Endocrine responses to acute and chronic high-altitude exposure $(4300 \mathrm{~m})$ : Modulating effects of caloric restriction. Am. J. Physiol., Endocrinol. Metabolism, 290: E1078-E1088. DOI: 10.1152/ajpendo.00449.2005 0193-1849/06

Basu, M., K. Pal, R. Prasad, A.S. Malhotra, K.S. Rao and R.C. Sawhney, 1997. Pituitary, gonadal and adrenal hormones after prolonged residence at extreme altitude in man. Int. J. Androl., 20: 153-158. PMID: 9354184

Basu, M., K. Pal. A.S. Malhotra, R. Prasad and R.C. Sawhney, 1995. Free and total thyroid hormones in humans at extreme altitude. Int. J. Biometeorol., 39: 17-21. DOI: 1007/BF01320888

Beall, C.M., C.M. Worthman, J. Stallings, K.P. Strohl and G.M. Brittenham et al., 1992. Salivary testosterone concentration of Aymara men native to $3600 \mathrm{~m}$. Ann. Hum. Biol., 19: 67-78. DOI: 10.1080/03014469200001932

Braverman, L.E. and R.D. Utiger, 2000. The Thyroids: A Fundemental and Clinical Text. 8th Edn., Lippincott William and Wilkins, USA., ISBN: 10: 0781721938, pp: 129.

Campbell, G.A., M. Kurcz, S. Marshall and J. Meites, 1977. Effects of starvation in rats on serum levels of follicle stimulating hormone, luteinizing hormone, thyrotropin, growth hormone and prolactin; Response to LH-releasing hormone and thyrotropin releasing hormone. Endocrinology, 100: 580-587. DOI: 10.1210/endo-100-2-580 
Central Department of Statistic and Information, 2004. Ministry of Economy and planning, Kingdom of Saudi Arabia. Detailed results population and housing Census 1425 H. http://www.mep.gov.sa

Climate Atlas of Saudi Arabia, 1988. Riyadh, Saudi Arabia: Ministry of Agriculture and Water. http://www.worldatlas.com/webimage/countrys/asi a/sa.htm

Du, J.Z., 1998. The Brain CRF During Hypoxia. In: Progress in Mountain Medicine and High Altitude Physiology, Matsumoto, Ohno H., T. Kolayash, S. Masuyama and M. Nakashimas (Eds.). Press Committee of Congress, pp: 416-417.

Eckes, L., 1976. Altitude adaptation. IV. Fertility and reproduction at high altitudes. Gegenbaurs Morphol. Jahrb. 122: 761-770. PMID: 1010291

Farias, J.G., E. Bustos-Obregon, R. Orellana, J.L. Bucarey and E. Quiroz et al., 2005. Effects of chronic hypobaric hypoxia on testis histology and round spermatid oxidative metabolism. Andrologia, 37: 47-52. PMID: 15644063

Fry, R.W., A.R. Morton, P. Garcia-Webb and D. Keast, 1991. Monitoring exercise stress by changes in metabolic and hormonal responses over a 24-h period. Eur. J. Applied Physiol., 63: 228-234. PMID: 6145124

Germack, R., F. Leon-Velarde, R. Valdes de la Barra and J. Farias et al., 2002. Effect of intermittent hypoxia on cardiovascular function, adrenoceptors and muscarinic receptors in Wistar rats. Exp. Physiol., 87: 453-460. PMID: 12392109

Givern, R.F. and E. Redei, 1994. Adrenalectomy reverse stress induced suppression of lutenizing hormone secretion in long term ovariectomized rats. Physiol. Behav., 55: 1147-1150. DOI: 10.1016/0031-9384(94)90402-2

Godoy, R.A., 1984. Human fertility and land tenure in highland Bolivia. Soc. Biol., 31: 290-297. PMID: 6545475

Golstein-Golaire, J., L. Vanhaelst, O.D. Bruno, R. Leclercq and G. Copinschi, 1970. Acute effects of cold on blood levels of growth hormone, cortisol and thyrotropin in man. J. Applied Physiol., 29: 622-626. PMID: 5482397

Gordon, A.S., F.J. Tornetta, A. Savino, S.A. D'angelo and H.A. Charipper, 1943. Effects of low atmospheric pressures on the activity of the thyroid, reproductive system and anterior lobe of the pituitary in the rat. Endocrinology, 33: 366-383. DOI: 10.1210/endo-33-6-366

Gosney, J.R., 1984. Effects of hypobaric hypoxia on the Leydig cell population of the testis of the rat. J. Endocrinol., 103: 59-62. DOI: 10.1677/joe.0.1030059
Gow, S.M., J. Seth, G.J. Beckett and G. Douglas, 1987. Thyroid function and endocrine abnormalities in elderly patients with severe chronic obstructive lung disease. Thorax, 42: 520-525. PMID: 3125626

Hackney, A.C., W.E. Sinning and B.C. Bruot, 1988 Reproductive profiles of endurance of trained and untrained males. Med. Sci. Sports Exerc., 20: 60-65. PMID: 3343919

Hamad, N. and S.P. Travis, 2006. Weight loss at high altitude: Pathophysiology and practical implications. Eur. J. Gastroenterol. Hepatol., 18: 5-10. PMID: 16357612

Heath, D. and D.R. Williams, 1977. Man at High Altitude. Longman Group Limited, Churchill Livingstone.

Hirooka, Y., C.S. Hollander, S. Suzuki, P. Ferdinand and S.I. Juaan, 1978. Somatostatin inhibits release of thyrotropin-releasing factor from organ cultures of rat hypothalamus. Proc. Natl. Acad. Sci., 75: 4509-4513. PMID: 100786

Hornbein, T.F., 1962. Adrenal cortical response to chronic hypoxia. J. Applied Physiol., 17: 264-248. PMID: 14448950

Humpeler, E., F. Skrabal and G. Bartsch, 1980. Influence of exposure to moderate altitude on the plasma concentration of cortisol, aldosterone, rennin, testosterone and gonadotropins. Eur. J. Applied. Physiol., 17: 167-176. PMID: 6780338

Jurgens, G., H.R. Christensen, K. Brosen, J. Sonne and S. Loft et al., 2002. Acute hypoxia and cytochrome P450-mediated hepatic drug metabolism in humans. Clin. Pharm. Ther., 71: 2140-2120. DOI: 0.1067/mcp.2002.121789

Knol, B.W., 1991. Stress and the endocrine hypothalamus pituitary testis system: Rev. Vet. Q., 13: 104-114. PMID: 1882489

Krishnamachary, B., S. Berg-Dixon, B. Kelly, F. Agani and D. Feldser et al., 2003. Regulation of colon carcinoma cell invasion by hypoxia-inducible factor 1. Cancer. Res., 63: 1138-1143. PMID: 12615733

Mayfield, D., 1980. Neuroendocrinology: A science for psychosomatic medicine. Psychosomat., 21: 971-972. PMID: 7208765

Michiels, C., 2004. Physiological and pathological responses to hypoxia. Am. J. Pathol., 164: 1875-1882. PMID: 15161623

Moncloa, F., I. Velasco and L. Betala, 1968. Plasma cortisol concentration and disappearance rate of 414C-Cortisol in new-comers to high altitude. J. Clin. Endocrinol. Metab., 28: 379-382. DOI: 10.1210/jcem-28-3-379 
Moncloa, F., J. Donayre, L.A. Sobrevilla and R. Guerra-Garcia, 1965. Endocrine studies at high altitude. II. Adrenal cortical function in sea level natives exposed to high altitudes $(4300 \mathrm{~m})$ for two weeks. J. Clin. Endocrinol. Metab., 25: 1640-1642. DOI: 10.1210/jcem-25-12-1640

Monge, C., 1943. Chronic mountain sickness. Physiol. Rev., 23: 166-184.

Mordes, J.P., F.D. Blume, S. Boyer, M.R. Zheng and L.E Braverman, 1983. Highaltitude pituitarythyroid dysfunction on Mount Everest. New England J. Med., 308: 1135-1138. PMID: 6835338

Orr, T.E. and D.R. Mann, 1992. Role of Glucocorticoids in the stress induced suppression of testicular steroidogenesis in adult male rats. Hormone Behav., 26: 350-363. PMID: 1398554

Panesar, N.S., 2000. Is steroid deficiency the cause of tolerance in nitrate therapy? Med. Hypotheses, 55: 310-313. PMID: 11000058

Panesar, S. and K.W. Chan, 2000. Decreased steroid hormone synthesis from inorganic nitrite and nitrate. Studies in vitro and in vivo. Toxic. Applied Pharm., 169: 222-230. DOI: 10.1006/taap.2000.9079

Pelley, J., 2003. Nitrate eyed as endocrine disrupter. Environ. Sci. Tech., 37: 162. PMID: 12775028

Pirke, K.M., R. Sintermann and H.J. Vogt, 1980. Testosterone and testosterone precursors in the spermatic vein and in the testicular tissue of old men. Reduced oxygen supply may explain the relative increase of testicular progesterone and 17 alpha-hydroxyprogesterone content and production in old age. Gerontology, 26: 221-230. PMID: 7372101

Richalet, J.P., R Kacimi and A.M. Antezana, 1992. The control of cardiac chronotropic function in hypobaric hypoxia. Int. J. Sports Med., 13: 22-24. PMID: 1336483

Richalet, J.P., V. Rutgers, P. Bouchet, J.C. Rymer and A. Keromes et al., 1989. Diurnal variations of acute mountain sickness, colour vision and plasma cortisol and ACTH at high altitude. Aviat. Space Environ. Med., 60: 105-111. PMID: 2539079

Sawhney, R.C. and A.S. Malhotra, 1991. Thyroid function in sojourners and acclimatized low landers at high altitude in man. Hormone and Metabol. Res., 23: 81-84. PMID: 2045063
Surks, M.I., 1966. Elevated PBI, free thyroxine and plasma protein concentration in man at high altitude. J. Applied Physiol., 21: 1185-1190. PMID: 4161959

Sutton, J.R., 1977. Effect of acute hypoxia on the hormonal response to exercise. J. Applied Physiol., 42: 587-592. PMID: 863820

Sutton, J.R., M.J. Coleman, J. Casey and L. Lazarus, 1973. Androgen responses during physical exercise. Brit. Med. J., 1: 520-522. DOI: 10.1136/bmj.1.5852.520

Tamasy, V., E. Meisami, J.Z. Du and P.S. Timiras, 1986. Exploratory behavior, learning ability and thyroid hormonal responses to stress in female rats rehabilitating from postnatal hypothyroidism. Dev. Psychobiol, 19: 537-553. PMID: 3803723

Tapia-Arancibia, L., S. Arancibia and H. Astier, 1984. $\mathrm{K}+$-induced thyrotropinreleasing hormone release from superfused mediobasal hypothalami in rats, Inhibition by somatostatin. Neurosci. Lett., 45: 47-52. PMID: 6145124

Vaernes, J.C., J.O. Owe and O. Myking, 1984. Central nervous reactions to a $6,5-\mathrm{h}$ altitude exposure at 3048 m. Aviat. Space Environ. Med., 55: 921-926. PMID: 6497822

Volek, J.S., W.J. Kraemer, J.A. Bush, T. Incledon and M. Boetes, 1997. Testosterone and cortisol in relationship to dietary nutrients and resistance exercise. J. Applied Physiol., 82: 49-54. PMID: 9029197

Ward, P.W., J.S. Millege and J.B. West, 1989. Altitude and Haemoglobin Concentration. In: High Altitude Medicine and Physiology, Ward, P.W., J.S. Millege and J.B. West (Eds.). Chapman and Hall, London, pp: $170-171$.

Westerterp, K.R. and B. Kayser, 2006. Body mass regulation at altitude. Eur. J. Gastroenterol. Hepatol., 18: 1-3. PMID: 16357611

Wiley, A.S., 1998. The ecology of low natural fertility in Ladakh. J. Biosoc. Sci., 30: 457-480. DOI: 10.1017/S002193209800457X 